\title{
Mooring loads analysis of submersible aquaculture cage system using finite element method
}

\author{
Tae-Ho KIM* \\ Department of Marine Production Management, Yosu National University, Yeosu 550-749, Korea
}

The expansion of near shore aquaculture is feasibility of moving aquaculture facilities into the open ocean. Numerical modeling technique using finite element method was used to enable the optimum design and evaluation of submersible aquaculture cage system. The characteristics of mooring loads response in mooring lines under waves and current and their response amplitude operators were calculated for single and three point mooring configuration at the surface condition and submerged one. The static mooring loads without wave and current loading were similar for both the surface and submerged configuration. It was calculated that three point mooring was more adequate than single point mooring for the mooring configuration of submersible aquaculture cage system. The wave induced response amplitude operators for the single point mooring configuration with the influence of currents were identical to those without the influence of currents.

Key words : Mooring loads, Submersible aquaculture cage system, Finite element method, Response amplitude operators

\section{Introduction}

Since wild fish stocks decline in Korean offshore and coastal waters, marine aquaculture is expected to play an increasing role in satisfying the national need for sea food. Marine aquaculture has been predominantly performed in the protected near shore waters of Korea. As environment and utilization issue put pressure an existing near shore aquaculture facilities, it is necessary to move suitable sites of fish farms from sheltered inshore waters to more exposed sites.

While inshore aquaculture has reached its full potential, a great potential exists for offshore aquaculture industry to grow if additional high-valued marine finfish products can be cultured. Therefore offshore aquaculture is one of the most promising methods in order to attain a sufficient production of marine food in the future. To obtain optimum growth and survival of fish under extreme conditions, the offshore fish cage system should be carefully designed and verified to protect the structural safety of the unit and the environment of the fish(Fredriksson et al., 2003a). However, most of traditional fish cages in Korea which consist of wooden frames with nets mounted under neath are inadequate for offshore fish cage system due to their material weakness and poor structural design.

An offshore submersible aquaculture cage system, consisting a modified gravity cage with three primary structural components, the monitor float, the upper rim and the lower rim was designed for an exposed site over $50 \mathrm{~m}$ depth of water in Korea. The system was conservatively designed to withstand environmental

*Corresponding author: thkim@yosu.ac.kr Tel: 82-61-659-3121 Fax: 82-61-659-3120 
loads under waves and current by submerged operation into mid the water in case of severe conditions.

A numerical model analysis was conducted to investigate the dynamics of submersible aquaculture cage system. The numerical modeling plays an important role in the design of cost-effective open ocean aquaculture technologies since they are simpler and less costly than full scale observations.

The engineering analysis of fish cage system has been addressed to a certain extent. Linfoot and Hall(1986) applied transfer function and frequency analysis to irregular wave data sets collected form a set of physical modeling tests. Aarsnes et al.(1990) conducted model test on current forces on cage, net deflection. Matsubara(1990) and Kim et al.(2000) carried out model tests and numerical modeling on the linear dynamic response of floating fish cages under waves and current. Ormberg(1991) and Ormberg and Slattelid(1993) investigated nonlinear response analysis of offshore fish cage systems. Fujita and Nishinokubi(1991) and Fu et al.(1994) analyzed mooring method of floating fish cages in regular wave by model tests. Gignoux and Messier(1999) adapted a commercially available finite element computer program to study fish cage dynamics in simulated waves. Gosz et al.(1999) applied to finite element modeling for the analysis of submerged cage system. Fredriksson et al.(1999a, 1999b, 2003a, 2003b, 2004) investigated mooring system and fluid dynamics of gravity type and submerged fish cages using model tests and finite element modeling. Colbourne and Allen(2001) conducted a field experiment measuring waves and the load and motion response of gravity type net-pen and compared the results with physical models.

Because most of above studies were carried out on floating fish cage system, it is necessary to conduct study on the hydrodynamic characteristics of submersible aquaculture cage system. The objective of this study is to determine mooring load characteristics of a specific submersible aquaculture cage with two different mooring designs in response to typical storm activity in the along the coast of Korea. A numerical model analysis using finite element method in this study was performed by both mooring configurations with the cage at the surface condition and submerged one using local environmental data as forcing input. In addition, the response amplitude operators are calculated for wave numbers obtained with and without the influence of the currents.

\section{Materials and methods}

\section{Submersible aquaculture cage system}

The submersible aquaculture cage system is octagonal type and consists of a modified gravity cage with three primary structural components, (1) the monitor float, (2) the upper rim and (3) the lower rim. These components are held together with tension wire $\# 1$ to \#3 made of vinyl coated stainless-steel wire. The cage system can be submerged through an arrangement of pulley systems operated by underwater motor in case of emergency situation, typhoon, high waves, red tide, sea pollution, etc. The cage system would be

Table 1. Particulars of submersible aquaculture cage system

\begin{tabular}{|c|c|c|}
\hline Components & Parameter & Value \\
\hline \multirow{3}{*}{ Handrail } & Length & $0.8 \mathrm{~m}$ \\
\hline & Diameter & $42.7 \mathrm{~mm}$ \\
\hline & Material & Stainless steel(STS) \\
\hline \multirow{3}{*}{ Monitor float } & Height & $0.5 \mathrm{~m}$ \\
\hline & Diameter & $3.7 \mathrm{~m}$ \\
\hline & Material & STS \\
\hline \multirow{3}{*}{ Tension wire \#1 } & Length & $5 \mathrm{~m}$ \\
\hline & Diameter & $22 \mathrm{~mm}$ \\
\hline & Material & STS 304(Vinyl coated) \\
\hline \multirow{3}{*}{ Upper rim } & No. of sections & 6 \\
\hline & Nominal diameter & $12 \mathrm{~m}$ \\
\hline & Material & Steel pipe(Galvanized) \\
\hline \multirow{3}{*}{ Tension wire \#2 } & Length & $12 \mathrm{~m}$ \\
\hline & Diameter & $22 \mathrm{~mm}$ \\
\hline & Material & STS 304(Vinyl coated) \\
\hline \multirow{3}{*}{ Lower rim } & No. of sections & 6 \\
\hline & Nominal diameter & $7 \mathrm{~m}$ \\
\hline & Material & Steel pipe(Galvanized) \\
\hline \multirow{3}{*}{ Tension wire \#3 } & Length & $4.8 \mathrm{~m}$ \\
\hline & Diameter & $22 \mathrm{~mm}$ \\
\hline & Material & STS 304(Vinyl coated) \\
\hline \multirow{3}{*}{ Bridle/swivel } & Thickness & $45 \mathrm{~mm}$ \\
\hline & Diameter & $0.6 \mathrm{~m}$ \\
\hline & Material & Steel(Galvanized) \\
\hline
\end{tabular}


submerged by $15 \mathrm{~m}$ below the mean water line. The general dimensions of the cage are provided in Table 1. The volume of the cage is maintained by having flotation at the top and rim and tension wire of the structure. The total volume of the system is modeled at approximately $1800 \mathrm{~m}^{3}$. The nominal diameter of upper rim which made of with galvanized steel is $12 \mathrm{~m}$. The bottom of cage is approximately $7 \mathrm{~m}$ in diameter and is also made with galvanized steel. The bottom also has a chain bridle which connects to mooring line.

The general configuration of the cage with the primary structural components is shown in Fig. 1. In this analysis, the system model incorporates the cage with two mooring configurations. The first configuration consists of a single, high tension mooring line that passes from the surface, through the cage and is moored at the bottom. The second configuration is three point mooring, the same as the first except three additional anchor legs attached to the upper frame. The cage is secured in a single point mooring by 1 deadweight anchor and three point mooring, the single point mooring cage system with three additional anchor legs by 4 deadweight anchors. The mooring lines are made of high strength polyethylene rope named Dyneema. The containment net of the cage is

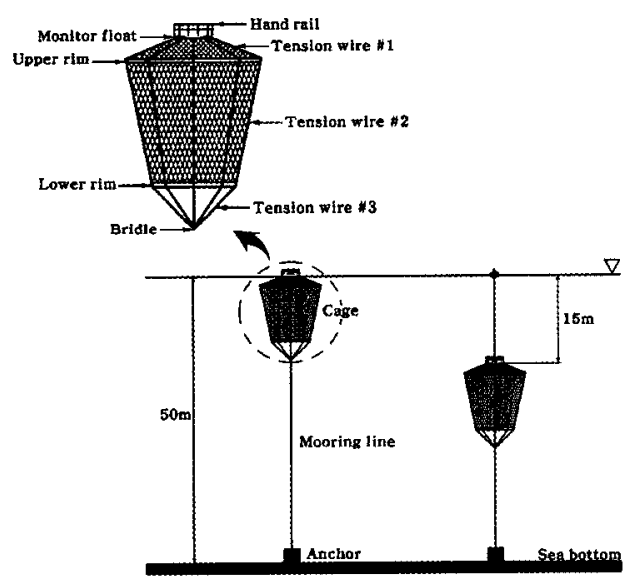

(a)

(b)

Fig. 1. Construction details of the submersible aquaculture cage system.
(a) Surface
(b) Submerged

made of square type Nylon netting $(\operatorname{Td} 210 \times 60)$ with mesh size of $60.6 \mathrm{~mm}$.

The three point mooring is based on the system having bridle lines run to compensator floats. These floats would sit at the surface with the cage, and would be pulled underneath the water when the cage is submerged. Mooring lines connect the compensator floats to the seafloor. The single point mooring remained in the system, however, because that is the means to submerge the cage.

Due to the octagonal shape of the cage, the bride lines are distributed around the rim as shown in Fig. 2. This orientation allows the line absorbing the tension

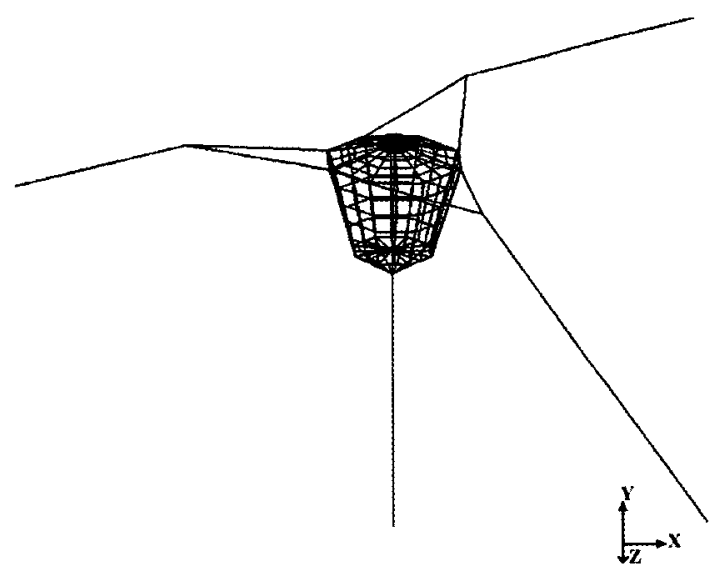

Fig. 2. Submersible aquaculture cage system analyzed with a single point mooring configuration with three additional anchor legs connect to the upper rim.

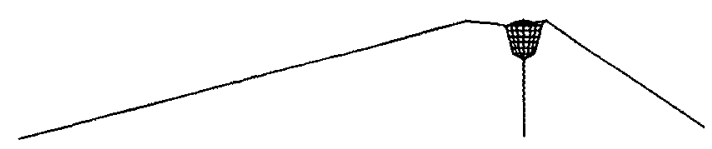

(a)

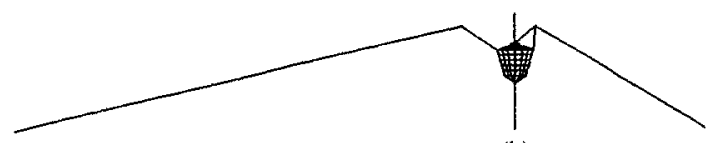

(b)

Fig. 3. Side view of the cage in the three point mooring while at the surface and submerged position.
(a) Surface
(b) Submerged 
to distribute the load to the rim without pinching any sections. The length of mooring line is set to have a $4: 1$ scope, with a length of $200 \mathrm{~m}$ at the depth of $50 \mathrm{~m}$. The bridle lines are connect to the upper rim to the compensator floats, joining the mooring line approximately $25 \mathrm{~m}$ from the center of the cage rim. A schematic of this cage system in the three point mooring at the surface and submerged mode is shown in Fig. 3.

\section{Numerical model}

\section{Background}

Numerical model simulations were performed using a finite element method computer program developed specifically for marine aquaculture applications, which name is Aqua-FE. The program was validated by a series of model tests and field measurements (Fredriksson et al., 2003a, 2003b, 2004; Tsukrov et al., 2003). Wave and current loadings on truss and buoy elements were introduced by utilizing the Morison equation adopted for the analysis of the aquaculture net pen systems by Gosz et al.(1996). The algorithm employs a nonlinear Lagrangian formulation to account for large displacements of structural elements. Hydrodynamic forces on the structural elements were calculated using the Morison equation modified to account for relative motion between the structural element and the surrounding fluid as described by Haritos and He(1992). The numerical modeling approach is to use a net element that is constructed to reproduce the drag, buoyancy, inertial and elastic forces that are exerted on the structure by currents and waves. Following Haritos and $\mathrm{He}(1992)$, the fluid force per unit length acting on a cylindrical element is represented as

$$
f=C_{1} \boldsymbol{V}_{R n}+C_{2} \boldsymbol{V}_{R t}+C_{3} \dot{\boldsymbol{V}}_{n}+C_{4} \dot{\boldsymbol{V}}_{R n}
$$

Where $V_{R n}$ and $V_{R t}$ are thenormal and tangential components of the fluid velocity relative to the structural element, $\dot{V}_{n}$ the normal component of total fluid acceleration and $\dot{V}_{R n}$ the normal component of fluid acceleration relative to the structural element. Bold letters are used to denote vectors and matrices. The coefficients in the above formula are given by $C_{1}=$ $\frac{1}{2} \rho_{w} D C_{n}\left|V_{R n}\right|, C_{2}=C_{1}, C_{3}=\rho_{w} A$ and $C_{4}=\rho_{w} A C_{m}$ where $D$ and $A$ are the diameter and the crosssectional area of the element in the deformed configuration, $\rho_{w}$ is the water density, $C_{n}$ and $C_{t}$ are the normal and tangential drag coefficients and $C_{m}$ is the added mass coefficient, respectively.

\section{Input parameters}

A simulation was performed for each of the mooring configurations with the cage at the surface and

Table 2. Wave and current parameters for each load case

\begin{tabular}{cccc}
\hline \multirow{2}{*}{$\begin{array}{c}\text { Load } \\
\text { case }\end{array}$} & $\begin{array}{c}\text { Weight } \\
(\mathrm{m})\end{array}$ & $\begin{array}{c}\text { Weriod } \\
(\mathrm{sec})\end{array}$ & $\begin{array}{c}\text { Current } \\
(\mathrm{m} / \mathrm{s})\end{array}$ \\
\hline 1 & 4 & 10 & 0.5 \\
2 & 4 & 10 & 1.0 \\
3 & 6 & 12 & 0.5 \\
4 & 6 & 12 & 1.0 \\
5 & 8 & 14 & 0.5 \\
6 & 8 & 14 & 1.0 \\
\hline
\end{tabular}

Table 3. Material properties of cage components used in the numerical model simulations

\begin{tabular}{cccc}
\hline Cage components & Mass density $\left(\mathrm{kg} / \mathrm{m}^{3}\right)$ & Young's modulus $(\mathrm{Pa})$ & Cross sectional area $\left(\mathrm{m}^{2}\right)$ \\
\hline Handrail & 2,080 & $1.90 \times 10^{11}$ & $1.90 \times 10^{11}$ \\
Handrail support & 3,266 & $1.90 \times 10^{11}$ & $5.81 \times 10^{-4}$ \\
Monitor float & 208 & $1.90 \times 10^{11}$ & $2.27 \times 10^{-1}$ \\
Tension wire & 6,400 & $2.00 \times 10^{11}$ & $3.14 \times 10^{-4}$ \\
Upper rim & 929 & $2.00 \times 10^{11}$ & $3.70 \times 10^{-2}$ \\
Lower rim & 1,216 & $2.00 \times 10^{11}$ & $2.10 \times 10^{-2}$ \\
Mooring line & 994 & $1.11 \times 10^{11}$ & $7.069 \mathrm{E}-04$ \\
Net & 1,140 & $6.158 \mathrm{E}-06$
\end{tabular}


submerged condition. A total of seven load cases were used as input to the model. The regular wave and current combinations for each load case are provided in Table 2. The range of wave heights and periods were chosen to be the characteristics of the design waves in the coast of Korea(Lee, 1986) which ranges from 4 to $8 \mathrm{~m}$ in wave heights and 10 to $14 \mathrm{sec}$ in period. The maximum current velocity is not expected to exceed $1 \mathrm{~m} / \mathrm{s}$ at the target site and the applied current is consistent with depth and water at the site is $50 \mathrm{~m}$ deep.

One of the load cases consists of a static simulation where no waves or currents are applied. The cage and mooring component material and geometric properties used in the numerical model simulations are provided in Table 3.

\section{Representation of numerical model}

In the first set of dynamic simulations, the submersible aquaculture cage system was analyzed using the single point mooring. In this configuration, the cage was modeled at the surface and submerged condition. Simulations were performed using each of the load cases provided in Table 2. The numerical model representation of this system is shown in Fig. 4, which includes the locations of the elements. The mooring load of submersible aquaculture cage were examined by averaging the appropriate locations shown in Fig.

4. The mooring loads analyzed were consistent for each of the load cases. The load values from above and below the cage were acquired at the submerged configuration.
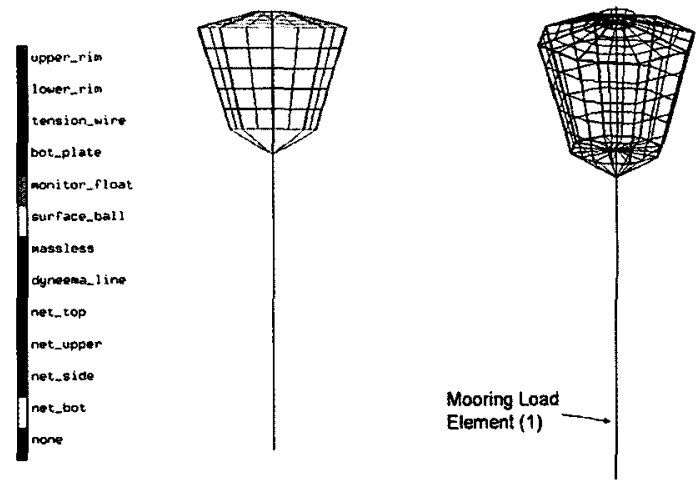

(a)
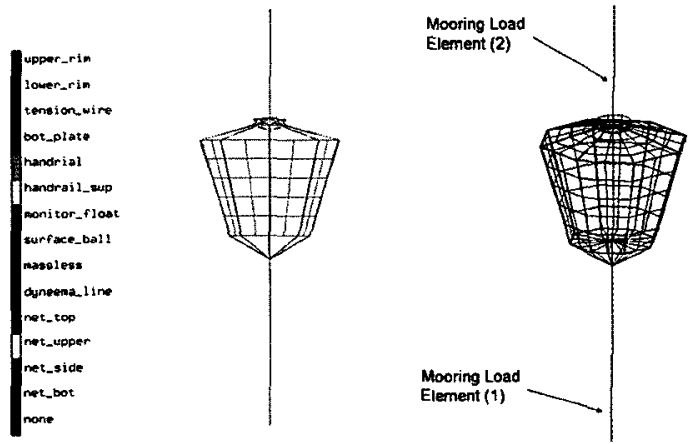

(b)

Fig. 4. Numerical model representation of the single point mooring cage system and location of the elements analyzed for mooring loads at the surface and submerged configuration.

(a) Surface (b) Submerged
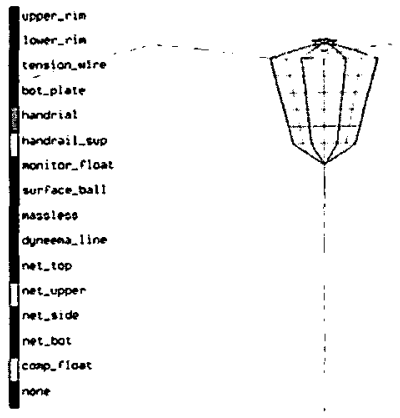

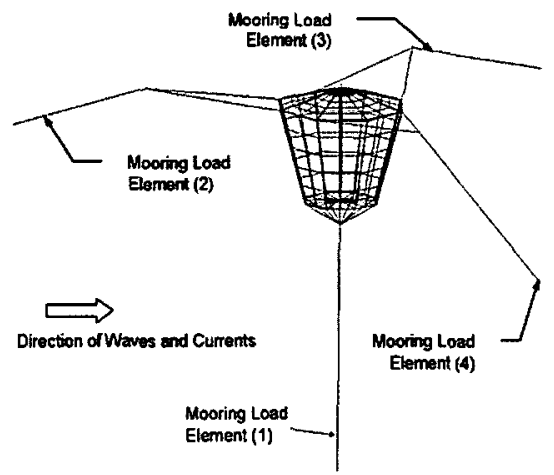

(a) 

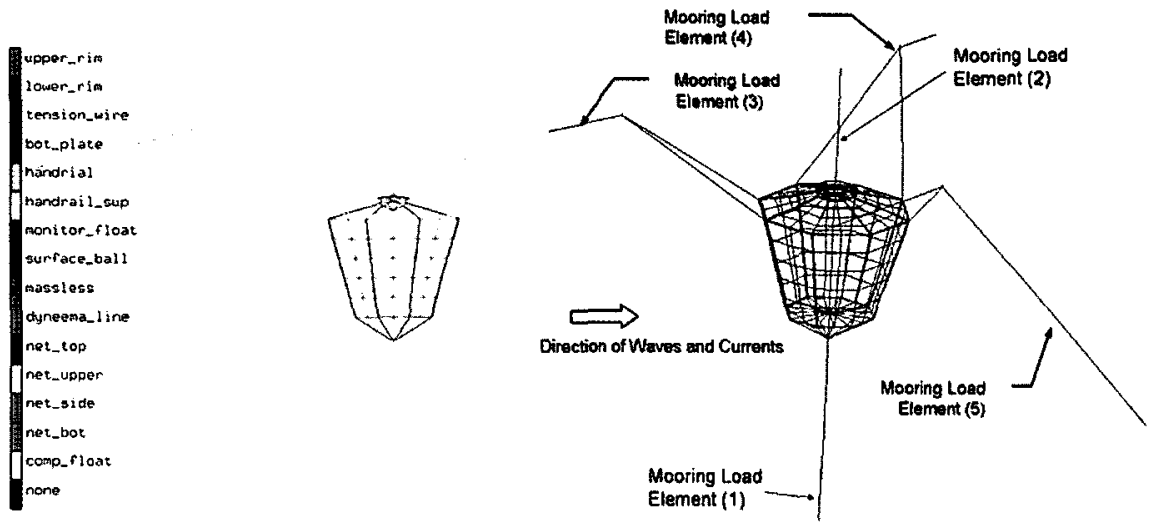

(b)

Fig. 5. Numerical model representation of the single point mooring cage system with three additional anchor legs and the location of the elements analyzed for mooring loads at the surface and submerged configuration.
(a) Surface
(b) Submerged

Similar numerical model simulations were performed using the single point mooring with three anchor legs shown in Fig. 5. In addition, Fig. 5 shows the locations of the elements chosen for mooring load calculations at the surface and submerged configuration.

\section{Results and discussion}

\section{Mooring loads}

The first set of numerical model simulations was performed without wave and current loading. In each of the simulations, the buoyancy of the cage created vertical motion as the mooring lines stretched, pretensioning the components. The static loads for only the single point mooring configuration were reported, since the values were nearly identical mooring with the three additional mooring legs. The calculated static loads at single point mooring was $25.13 \mathrm{kN}$ at the surface and $23.49 \mathrm{kN}$ at the submerged configuration, respectively. The results were similar for both the surface and submerged configuration, because the cage was positioned just beneath the surface in the surface mode.

Once the static simulations were completed, dynamic simulations were performed for the single point mooring with the cage at the surface and submerged configuration. Fig. 6 shows the time series results of mooring loads for the single point mooring configuration. The values for maximum and average loads were provided in Table 4 . The maximum average load calculated in each load case was $72.45 \mathrm{kN}$ at the surface and $67.46 \mathrm{kN}$ at the submerged configuration. The average mooring load at the submerged was smaller by $11 \%$ than that at the surface for the single point mooring in the six load cases.

The next set of simulations consisted of the three point mooring with the cage at the surface and submerged configuration. The time series results were provided in Fig. 7. The values for maximum and average load were provided in Table 5. The maximum average load on mooring line \#1 in the six load cases was $36.02 \mathrm{kN}$ at the surface and $31.95 \mathrm{kN}$ at the submerged. In addition, the load on mooring line \#2 and $\# 3$ that is the direction of waves and current at surface and submerged was $69.09 \mathrm{kN}$ and $50.21 \mathrm{kN}$, respectively. The average mooring load on mooring line \#1 at the submerged was smaller by $24 \%$ than that at the surface and the load at submerged in the direction of waves and current was smaller by $39 \%$ than that at surfaced for the three point mooring in 


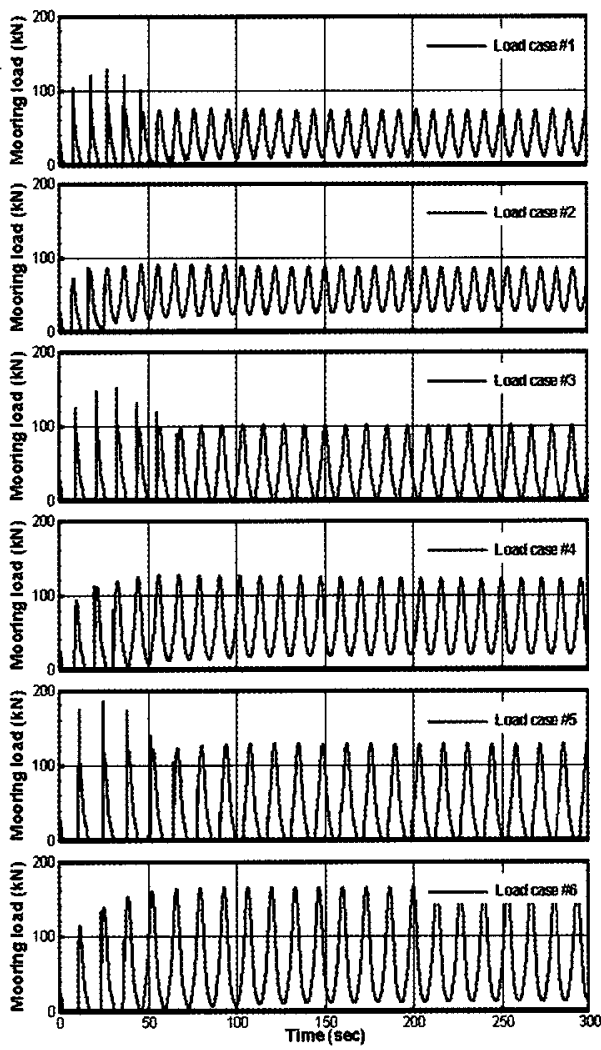

(a)
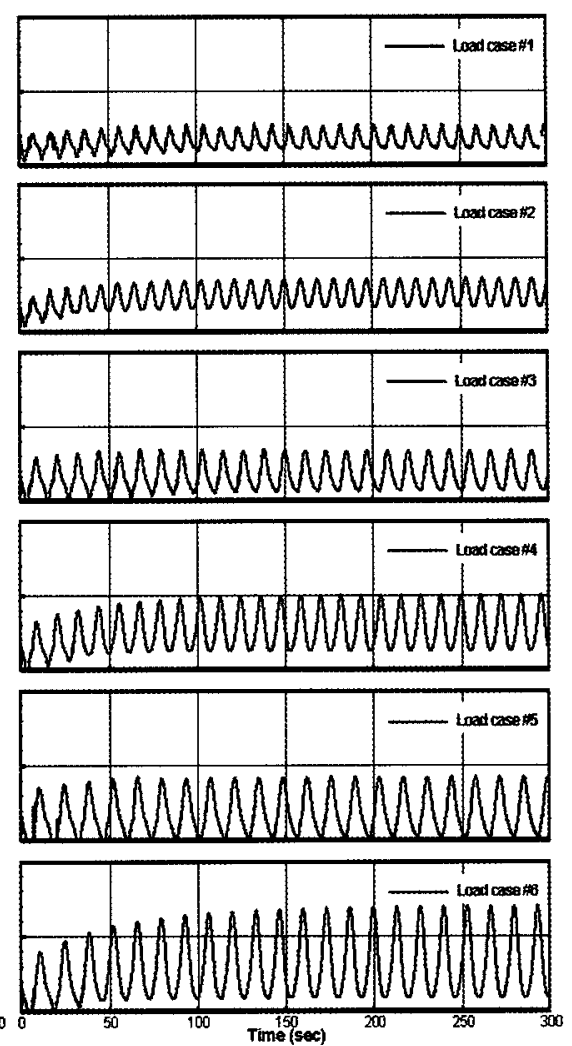

(b)

Fig. 6. Time series of mooring loads on the mooring line \#1 for the single point mooring.

(a) Surface (b) Submerged

Table 4. Mooring loads on the mooring line \#1 of submersible aquaculture cage for the single point mooring

(Unit: kN)

\begin{tabular}{ccccc}
\hline \multirow{2}{*}{$\begin{array}{c}\text { Load } \\
\text { case }\end{array}$} & \multicolumn{2}{c}{ Surface configuration } & \multicolumn{2}{c}{ Submerged configuration } \\
\cline { 2 - 5 } & Max. load & Mean load* & Max. load & Mean load* \\
\hline 1 & 129.40 & 39.20 & 56.41 & 33.93 \\
2 & 91.19 & 52.51 & 72.10 & 50.97 \\
3 & 151.27 & 40.68 & 69.70 & 34.84 \\
4 & 126.53 & 61.32 & 100.37 & 56.81 \\
5 & 185.21 & 46.89 & 85.53 & 38.94 \\
6 & 165.41 & 72.45 & 139.96 & 67.46 \\
\hline
\end{tabular}

*Mean load represents the average load after the system reached steady state motion.

each load case. It was calculated that three point mooring was more adequate than single point mooring for the mooring configuration of submersible aquaculture cage system.

As current increases at the same wave condition, mooring loads at the surface decrease but the loads at the submerged increase on the contrary, which means waves are predominantly factor to mooring load rather at the surface configuration than at the submerged one.

Because high snap loads act on the high tension mooring lines that consist of low-stretch rope, in addition, the use of Dyneema as mooring rope material may not perform as well as a material with more compliance.

During the simulation, the numerical model calculated a coefficient of drag value at every time $\operatorname{step}(\Delta t=1 \mathrm{sec})$ based on Reynolds number $(R e)$ using 

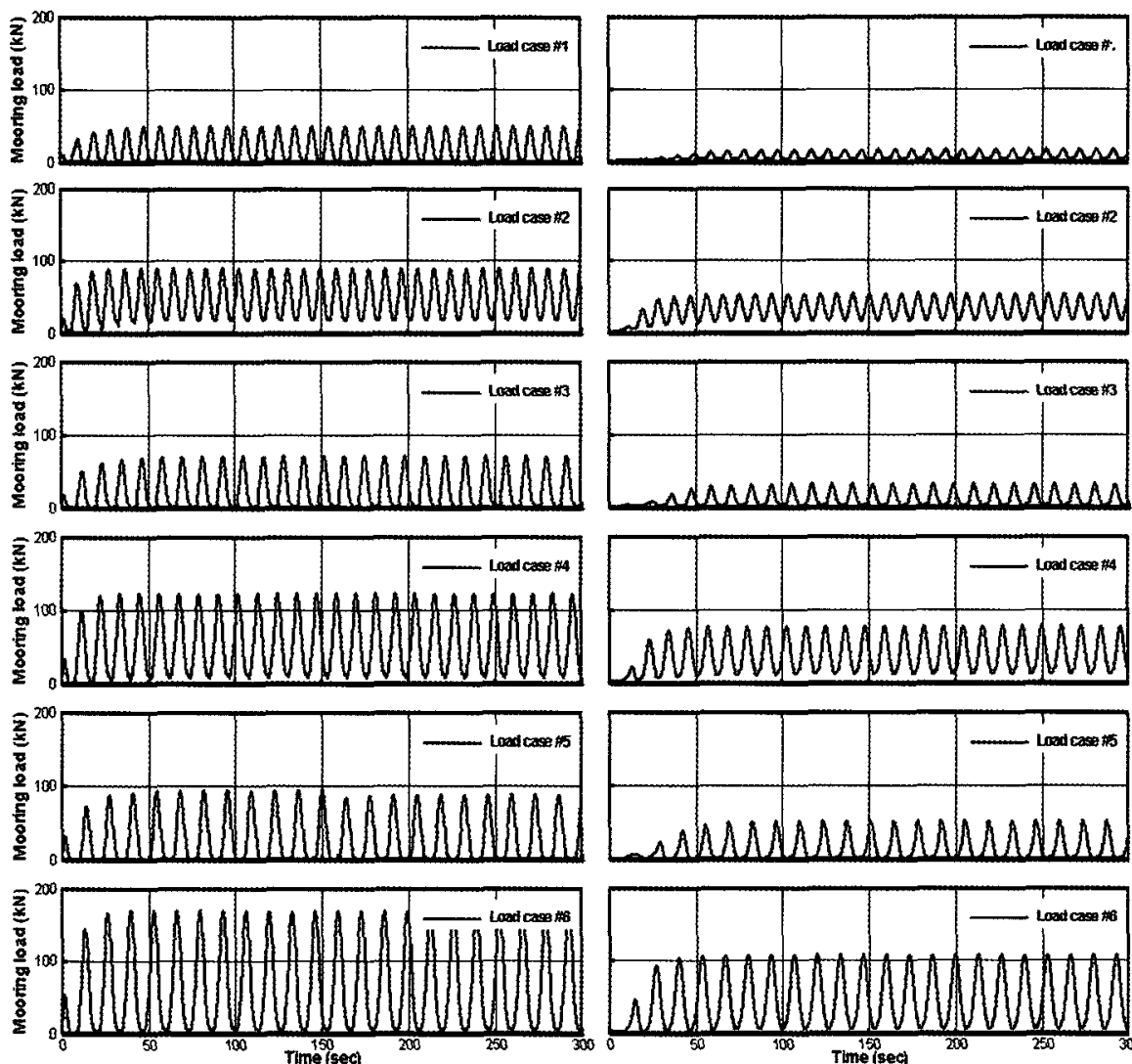

(a)
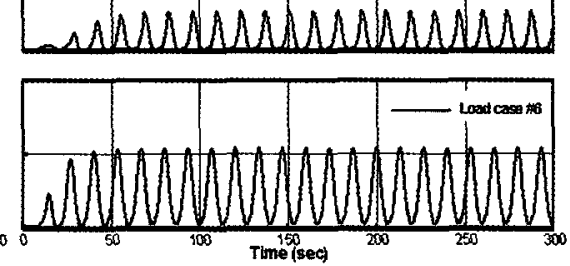

(b)

Fig. 7. Time series of mooring loads on the mooring line $\# 2$ and $\# 3$ for the three point mooring.

(a) Surface (b) Submerged

Table 5. Mooring loads on the mooring line $\# 1, \# 2$ and $\# 3$ of submersible aquaculture cage for the three point mooring

(Unit: $\mathrm{kN})$

\begin{tabular}{|c|c|c|c|c|c|c|c|c|}
\hline \multirow{2}{*}{$\begin{array}{l}\text { Load } \\
\text { Case }\end{array}$} & \multicolumn{4}{|c|}{ Surface configuration } & \multicolumn{4}{|c|}{ Submerged configuration } \\
\hline & $\begin{array}{l}\text { Max. } \\
\text { load } 1\end{array}$ & $\begin{array}{c}\text { Mean } \\
\text { load 1* }\end{array}$ & $\begin{array}{l}\text { Max. } \\
\text { load } 2\end{array}$ & $\begin{array}{c}\text { Mean } \\
\text { load 2* }\end{array}$ & $\begin{array}{l}\text { Max. } \\
\text { load } 1\end{array}$ & $\begin{array}{l}\text { Mean } \\
\text { load } 1^{*}\end{array}$ & $\begin{array}{c}\text { Max. } \\
\text { load } 3\end{array}$ & $\begin{array}{c}\text { Mean } \\
\text { load 3* }\end{array}$ \\
\hline 1 & 99.67 & 30.59 & 50.89 & 22.90 & 53.15 & 19.23 & 17.67 & 9.35 \\
\hline 2 & 70.54 & 32.90 & 89.77 & 50.62 & 60.86 & 27.99 & 54.36 & 34.86 \\
\hline 3 & 113.81 & 30.43 & 72,10 & 25.16 & 73.51 & 18.75 & 32.73 & 12.57 \\
\hline 4 & 92.60 & 31.86 & 122.29 & 56.37 & 81.29 & 26.42 & 77.75 & 41.09 \\
\hline 5 & 141.38 & 33.39 & 94.72 & 27.67 & 83.41 & 25.63 & 52.45 & 16.19 \\
\hline 6 & 115.22 & 36.02 & 168.24 & 69.09 & 96.13 & 31.95 & 108.86 & 50.21 \\
\hline
\end{tabular}

*Mean load 1, 2 and 3 represents the average load after the system reached steady state motion.

the empirical method described in Choo and Casarella(1971). This representation took into account coefficient of drag values for laminar $(1<\operatorname{Re}<30)$ and turbulent wake $\left(30<R e<10^{5}\right)$ flow regimes. The empirical method did not take into consideration coefficient of drag values where a full turbulent boundary layer exists. This may be the case for some of the larger diameter components at the higher velocity 
cases. As the coefficient of drag values in this flow regime can be considerably less, the drag loads of the system calculated by the model may be conservative.

\section{Response amplitude operators}

Linear transfer function magnitudes calculated for the deterministic waves referred to as response amplitude operators(RAOs) are defined as wave elevation amplitude to mooring load amplitude. In the model, the new wave number values were subsequently used to calculate the wave orbital velocities and incorporated with the steady state current into a form of Morison equation. In this study, the response amplitude operators were provided for wave numbers obtained with and without the influence of the currents.

Response amplitude operators were calculated for single point mooring configuration with the cage in the surface condition and submerged one for the six load cases shown in Table 2. The first set of RAOs were calculated using the wave excursion and slope amplitudes without the influence of the currents. The second set of RAOs were calculated using the wave excursion and slope amplitudes with the influence of currents. During the data processing procedures, the time series data used in the calculations were taken after the transient period of the simulation from 150 to $300 \mathrm{sec}$. The amplitudes of the response for mooring loads were determined by finding all of the crests and troughs and added them together to obtain heights. Each of the height values in the time series was divided by 2 and then averaged to find the mean amplitudes of response. Then the RAOs were found by dividing by the input forcing, as described in the previous section.

The addition of currents superimposed on the wave field changes the effective characteristics of the waves. As with linear wave theory, it is assumed that the period remains constant as the wave propagates from still water onto a moving oceanic current. However, the wave length changes. In the situation where a wave propagates onto a current traveling in
Table 6. RAOs without the influence of currents for submersible cage cage at the single point mooring

(Unit: kN/m)

\begin{tabular}{ccc}
\hline $\begin{array}{c}\text { Load } \\
\text { case }\end{array}$ & Surface & Submerged \\
\hline 1 & 15.93 & 7.22 \\
2 & 15.27 & 9.65 \\
3 & 16.57 & 8.68 \\
4 & 17.31 & 12.36 \\
5 & 16.16 & 9.56 \\
6 & 19.26 & 15.05 \\
\hline
\end{tabular}

the same direction, the length of the wave increases. The length decreases, however, if the wave propagates onto a current traveling in the opposite direction.

Using these values, RAOs values of the mooring loads for the single point mooring in the surface configuration and submerged one were provided in Table 6. The RAOs with the influence of currents for the single point mooring were reported, since the values were identical to those without the influence of currents. The maximum RAOs of mooring loads were $19.26 \mathrm{kN} / \mathrm{m}$ at the surface configuration and $15.05 \mathrm{kN} / \mathrm{m}$ at the submerged one in the six load cases. In addition, the average RAOs at the submerged configuration were smaller by $38 \%$ than those at the surface one.

\section{Conclusion}

A finite element method was used to model the hydrodynamic responses of submersible aquaculture cage system which was at the surface and submerged for the single and three point mooring configuration to environmental loading. The static mooring loads without waves and current were similar for both the surface configuration and submerged one. It was calculated that three point mooring was more adequate than single point mooring for the mooring configuration of the submersible aquaculture cage system. The wave induced response amplitude operators with the influence of currents were identical to those without the influence of currents for the single point mooring configuration. Further verifications by simulation 
analysis under irregular waves, physical model and field measurements are needed for the purpose of analyzing more accurate mooring characteristics of the cage system.

\section{Acknowledgements}

This study was supported by Yosu National University through research fund.

\section{References}

Aarsnes, J.V., H. Rudi and G. Loland, 1990. Current forces on cage, net deflection. Engineering for offshore fish farming. Thomas Telford, London, 137-152.

Choo,Y.I. and M.J. Casarella, 1971. Hydrodynamic resistance of towed cables. J., Hydro., 126-131.

Colbourne, D.B. and J.H. Allen, 2001. Observations on motions and loadings in aquacultures from full scale and model scale measurements. Aquacultural Engineering, 24(2), $129-148$.

Fredriksson, D.W., E. Muller, M. Robinson Swift, I. Tsukrov and B. Celikkol, 1999a. Offshore grid mooring/net pen system; Design and physical modeling. Proc. of OMAE99, July 11-16, 1999, Newfoundland, Canada, OMAE99-3064, $1-8$.

Fredriksson, D.W., E. Muller, M. Robinson Swift and B. Celikkol, 1999b. Physical model tests of a gravity-type fish cage with a single point, high tension mooring. Proc. of OMAE99, July 11-16, 1999, Newfoundland, Canada, OMAE99-3066, 8-14.

Fredriksson, D.W., M. Robinson Swift, James D. Irish, lgor Tsukrov, and B. Celikkol, 2003a. Fish cage and mooring system dynamics using physical and numerical models with field measurements. Aquacultural Engineering, 27(2), $117-146$.

Fredriksson, D.W., M.J. Palczynski, M.R. Swift and J.D. Irish, 2003b. Fluid dynamic drag of a central spar cage, Open ocean aquaculture IV, June 17-20, St. Andrews, NB, Canada, Mississippi-Alabama Sea Grant Consortium, Ocean Springs, MS, MASGP-01-006, 151 - 168.

Fredriksson, D.W., J. DeCew, M.R. Swift, I. Tsukrov, M.D. Chambers, and B. Celikkol, 2004. The design and analysis of a four-cage, grid mooring for open ocean aquaculture. Aquacultural Engineering, 32(1), 77 - 94.

Fu, E. B., K. Nashimoto and K. Yamamoto, T. Hiraishi and T.
Takagi, 1994. Model experiment examination of mooring method in aquaculture net cage. Bulletin of the Faculty of Fisheries, Hokkaido University, 45(1), 9 - 18

Fujita, S., K. Fukahori and H. Nishinokubi, 1991. Tension of the mooring ropes on the net cage model of raft type in regular waves. Nippon Suisan Gakkashi, 57(12), $2229-2235$.

Gignoux, H. and R.H. Messier, 1999. Computational modeling for fin-fish aquaculture net pens. Oceanic engineering, 3(1), $12-22$.

Gosz, M.K, M.R. Swift, and B. Celikkol, 1996. Finite element modeling of submerged aquaculture net-pen systems in open ocean aquaculture. Proc. of an International Conf, May 8 - 10, 1996, Portland, Maine, MariePolk, Ed. New Hampshire/Maine Sea Grant College Program Rpt., \#UNHMP-CP-SG-96-9, 523 - 554.

Haritos, N and D.T. He, 1992. Modelling the response of cable elements in an ocean environment. Fin. Elem. in Analysis and Des., 19, 19-32.

Kim, T.H., J.O. Kim and C.R. Ryu, 2001. Dynamic motions of model fish cage systems under the conditions of waves and current. J. Korean Fish. Soc., 34(1), 43-50.

Lee, S.W., 1986. Physical oceanography. Gypmoondang, Seoul, pp. 268.

Linfoot, B.T. and M.S. Hall, 1986. Analysis of the motions of scale-model sea-cage systems. In: IFAC symposium: Aquaculture ' 86 , Automation and data processing in aquaculture, Trondheim, Norway, August 18-21.

Matsubara, Y., 1990. Dynamic response of offshore fish cage in the regular wave. Journal of the Japan Coastal Engineering Society, 37, 714-718.

Ormberg, H., 1991. Non-linear response analysis of floating fish farm systems. Ph.D. Thesis. Division of Marine Structures. The Norwegian Institute of Technology, Trondheim, pp. 159.

Ormberg, $\mathrm{H}$ and O.H. Slaattelid, 1993. Response analysis of floating fish farms. Proc. of The First International Conf. on Fish Farming Technology, 185-192.

Tsukrov, I., O. Eroshkin, D.W. Fredriksson, M.R. Swift, and B. Celikkol, 2003. Finite element modeling of net panels using consistent net elements. Ocean Engineering, 30, $251-270$

2005년 10월 10일 접수 2005년 12월 30일 수리 